\title{
Zinner syndrome: an updated pooled analysis based on 214 cases from 1999 to 2020: systematic review
}

\author{
Tianzhu Liu ${ }^{1 \#}$, Xiaodan Li $^{2 \#}$, Lesheng Huang ${ }^{1}$, Hongyi Li $^{1}$, Kaili Cai ${ }^{1}$, Jinghua Jiang ${ }^{1}$, Nianli Chen ${ }^{3}$, \\ Wanchun Zhang ${ }^{1}$, Jiahui Tang ${ }^{1}$, Meng Zhang ${ }^{1}$, Dan Zhao ${ }^{1}$, Jingzhi Ye ${ }^{1}$, Chengfeng Zhang ${ }^{1}$, Tao He ${ }^{1}$, \\ Bo Liu ${ }^{1}$, Yongsong Ye ${ }^{1}$, Jun Chen ${ }^{1}$
}

${ }^{1}$ Department of Radiology, Guangdong Hospital of Traditional Chinese Medicine, Zhuhai, China; ${ }^{2}$ Department of Gynecology, Guangdong Hospital of Traditional Chinese Medicine, Zhuhai, China; ${ }^{3}$ Department of Urology, Guangdong Hospital of Traditional Chinese Medicine, Zhuhai, China Contributions: (I) Conception and design: B Liu, Y Ye, J Chen; (II) Administrative support: J Tang, J Ye, C Zhang, T He; (III) Provision of study materials or patients: H Li, L Huang; (IV) Collection and assembly of data: K Cai, J Jiang, N Chen, W Zhang; (V) Data analysis and interpretation: T Liu, X Li, M Zhang, D Zhao; (VI) Manuscript writing: All authors; (VII) Final approval of manuscript: All authors.

\#These authors contributed equally to this work.

Correspondence to: Jun Chen; Bo Liu; Yongsong Ye. Department of Radiology, Guangdong Hospital of Traditional Chinese Medicine, No. 111 Dade Road, Zhuhai 519000, China. Email: junesums@163.com; liubogzcm@163.com; ye7yong7song@163.com.

\begin{abstract}
Zinner syndrome (ZS) is a rare anomaly of the Wolffian duct. We searched for case reports and case series to identify the most effective methods for examination and treatment. The PubMed/Medline, Embase, and Scopus databases were searched. Our searches yielded 160 case reports/case series and included 214 patients. The mean age at diagnosis was 29.35 years. The R:L distribution was 1:1. The most common symptoms were: frequency $(24.3 \%)$, dysuria (23.1\%) and perineal pain $(20.2 \%)$ in ZS patients with clinical symptoms. The diagnostic investigations used most frequently were magnetic resonance imaging (MRI) $(67.8 \%)$ and ultrasonography $(65.0 \%)$. Maximum flow rate on uroflowmetry, semen ejaculate volume, sperm count, and sperm motility were significantly lower in patients with ZS. Among 193 patients with treatment details, $65.8 \%$ underwent surgery; $9.8 \%$ underwent aspiration; $24.3 \%$ were followed with observation. Two patients died after surgery; all other patients remained asymptomatic after surgery. Fifty-two patients had complications and comorbidities. In patients with ZS, the most common symptoms are seminal vesicle cyst enlargement and compression of the bladder, ureter, and reproductive system. The diagnosis mostly depends on radiological examination. Surgery may be effective, but complications may occur.
\end{abstract}

Keywords: Zinner syndrome (ZS); symptom; diagnostic examinations; treatment; surgery; complication

Submitted Oct 10, 2020. Accepted for publication Dec 14, 2020.

doi: 10.21037/apm-20-1997

View this article at: http://dx.doi.org/10.21037/apm-20-1997

\section{Introduction}

Zinner syndrome $(\mathrm{ZS})$ is a very rare anomaly, which is associated with an embryologic abnormality that develops in the distal portion of the mesonephric or Wolffian duct between the 4th and 13th gestational week. Incomplete migration of the ureteric bud from the proximal portion of the mesonephric duct may also result in a failure to meet with the metanephros. This failure interferes with the ureteric bud's key role in differentiation of the metanephric blastema, and ipsilateral renal agenesis will occur, in addition to atresia of the ejaculatory duct. This leads to unsatisfactory drainage, subsequent distension of the seminal vesicle, and creation of a cystic structure (1).

The condition was first described by Zinner in 1914 (Figure 1). The incidence of ZS is very low. In one study of children in Taipei (2), the incidence of seminal vesicles with ipsilateral renal dysplasia was $0.0046 \%$ $(13 / 28,000)$. The clinical symptoms associated with this condition, which are nonspecific, include frequent dysuria, 

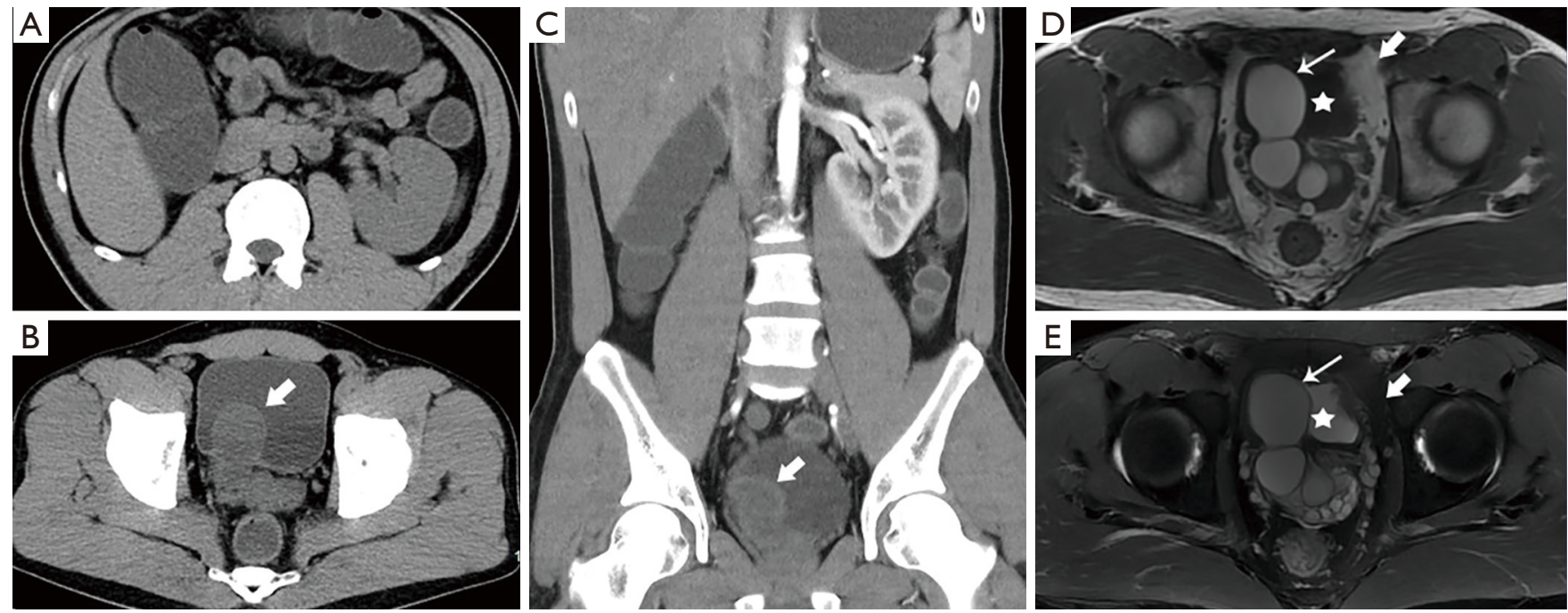

Figure 1 In a 30-year-old man with lower abdominal pain, CT presented the right renal agenesis (A) and posterior cystic lesions of the bladder (B,C, arrowheads). MRI showed the cystic lesions was attached to the right seminal vesicle and present as hyperintense in T1WI sequence and fat-suppression sequence (D,E) (short arrows) compared with bladder (stars) and fat (arrowheads). Operative and pathological findings as hemospermia in the seminal vesicle cyst. CT, computed tomography; MRI, magnetic resonance imaging.

epididymitis, perineal discomfort, and post-ejaculation pain. The severity of symptoms may correlate with the size of the seminal vesicle cyst (3). van den Ouden et al. (1) conducted a pooled analysis of patients with ZS in 1998. The study provided important reference information for clinicians and researchers; however, as times change and more cases are reported, an updated review of ZS cases may be necessary. We therefore performed a comprehensive review, which included case reports and case series published during the period from 1999 to 2020. We present our article in accordance with the PRISMA reporting checklist (available at http://dx.doi. org/10.21037/apm-20-1997).

\section{Methods}

A literature search was performed using the PubMed/ Medline, Embase, and Scopus databases and the language was no restrictions. Two physicians with literature retrieval experience performed the search using the following keywords: zinner syndrome; zinners syndrome; seminal vesicle cyst; ipsilateral renal agenesis; ipsilateral renal hypoplasia. Studies published during the period from January 1st, 1999 to May 1st, 2020 were included in the study. The data search was limited to case reports and case series. In order to identify other potentially eligible publications, the references from the articles identified initially were manually reviewed. The diagnosis of ZS was considered in cases with of seminal vesicle cyst formation combined with ipsilateral renal agenesis.

The case reports were analyzed with regard to the data provided on patient age, clinical symptoms, site of pathogenesis, urogenital function, results on diagnostic examinations, treatment options, duration of follow-up, prognosis, complications, and comorbidities. The research is being reported in line with the attached PRISMA reporting checklist.

\section{Statistical analysis}

Descriptive statistics were used to summarize the variables in the case reports and case series.

\section{Results}

In total, 160 case reports and case series (Table S1) were obtained from the PubMed/Medline, Embase, and Scopus databases (Figure 2). All these cases met the proposed diagnostic criteria for ZS, and 214 patients were ultimately included. 


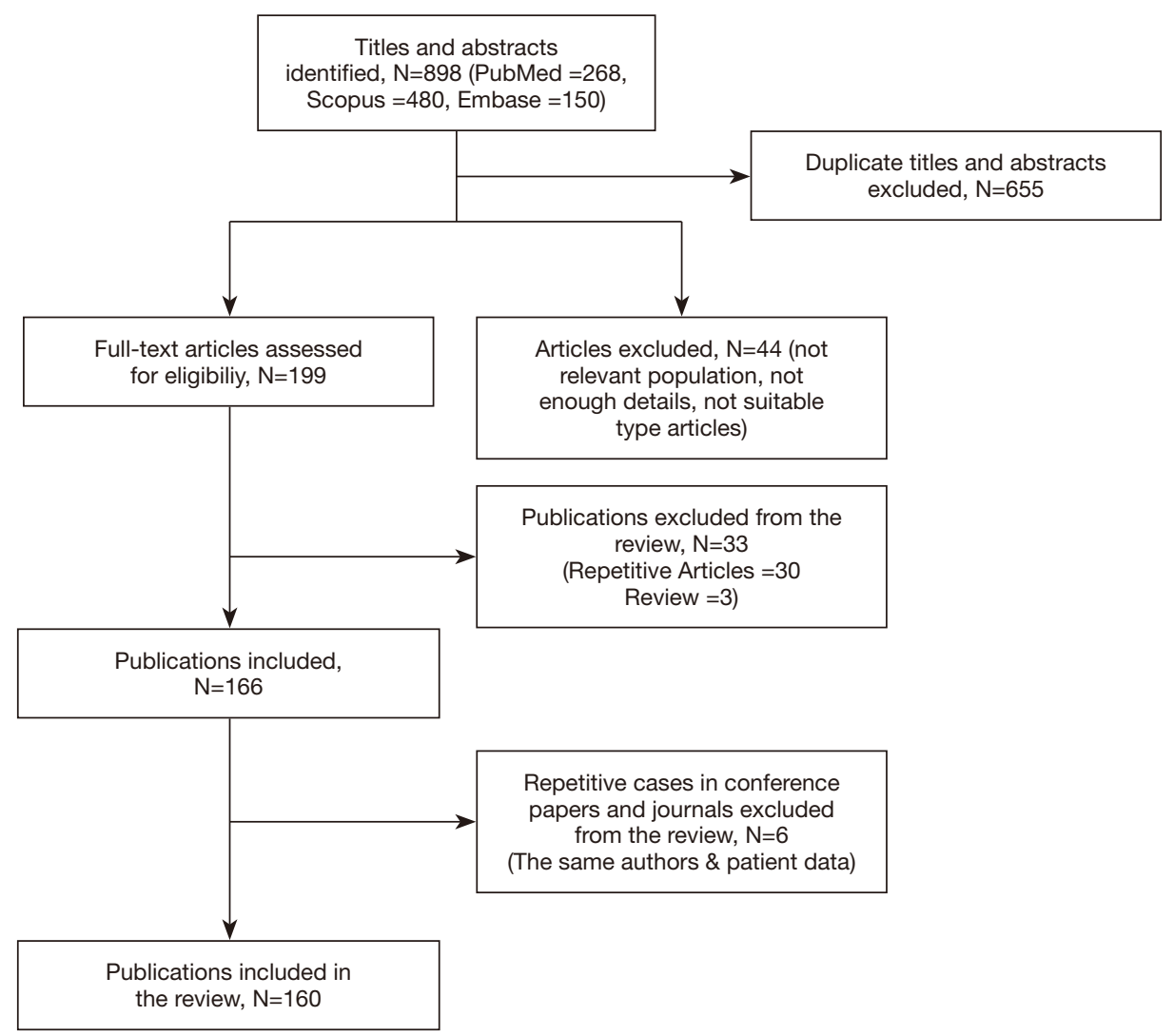

Figure 2 Flow-chart depicting the screening process.

\section{Patient characteristics at baseline}

Twenty-one patients were removed due to a lack of data $(4,5)$. The age of patients included in the study ranged from newborn (6) to 76 years (7) (mean age: 29.35 years) (Table 1). Of 214 patients, 173 (80.8\%) had clinical symptoms, while the remaining cases were detected incidentally without symptoms $(163 \%, 35 / 214)$, or had symptoms that were not described in detail $(3.3 \%, 7 / 214)$. The symptoms described in the included studies were diverse, and most patients presented with multiple symptoms. Most patients presented with urinary symptoms, including: urinary frequency $(24.2 \%, 42 / 173)$; dysuria $(26.0 \%$, $45 / 173)$; urinary urgency $(13.9 \%, 24 / 173)$; micturition pain $(8.2 \%, 14 / 173)$, hematuria $(7.5 \%, 13 / 173)$; nocturia $(1.7 \%, 3 / 173)$; urinary incontinence $(1.2 \%, 2 / 173)$. The other common symptoms reported included: local pain, including perineal pain $(20.2 \%, 35 / 173)$; abdominal pain (14.5\%, 25/173); pelvic pain $(6.9 \%, 12 / 173)$; suprapubic pain $(4.0 \%, 7 / 173)$; backache $(3.5 \%, 6 / 173)$; inguinodynia $(2.9 \%, 5 / 173)$; testicular pain $(1.7 \%, 3 / 173)$; scrotal pain
$(1.2 \%, 2 / 173)$; coxalgia $(0.6 \%, 1 / 173)$. Another category of symptoms in this patient population comprised abnormalities of reproductive function, including: infertility (13.9\%, 24/173); ejaculation-related pain (11.0\%, 19/173); hematospermia $(8.7 \%, 15 / 173)$; testicular swelling $(3.5 \%$, $6 / 173)$; reduced or negligible semen volume $(2.9 \%, 5 / 173)$; weak ejaculation $(2.9 \%, 5 / 173)$; sexual discomfort $(2.3 \%$, $4 / 173)$; erectile dysfunction $(1.2 \%, 2 / 173)$. Other symptoms reported included: constipation $(4.0 \%, 7 / 173)$, fever $(3.5 \%$, $6 / 173)$, pain on defecation $(1.2 \%, 2 / 173)$, loss of weight $(1.2 \%, 2 / 173)$, nausea and vomiting $(1.2 \%, 2 / 173)$, and so on. All reported symptoms are summarized in Table 2 and Figure 3. In cases with seminal vesicle cyst enlargement and compression of the bladder, the most significant symptoms may be dysuria, perineal pain, urinary frequency, and urinary urgency. In 110 patients (51.4\%), the seminal vesicle cyst and renal agenesis were present on the patient's right side. In 104 patients (48.6\%), the seminal vesicle cyst and renal agenesis were present on the patient's left side. Thus, the patient's right side was more commonly affected, but the R:L ratio was approximately $1: 1$. 


\section{Diagnostic examinations}

Table 3 summarizes the results of diagnostic examination for the 214 patients included in the study. Most patients underwent more than two diagnostic examinations. The techniques used most commonly for diagnosis were: magnetic resonance imaging (MRI) (145/214, 67.8\%),

Table 1 Distribution of age (in decades) at the time of presentation in 193 ZS patients

\begin{tabular}{lcc}
\hline Decade (year) & $\mathrm{N}$ & $\%$ \\
\hline $0-10$ & 23 & 11.9 \\
$11-20$ & 32 & 16.6 \\
$21-30$ & 64 & 33.1 \\
$31-40$ & 28 & 14.5 \\
$41-50$ & 23 & 11.9 \\
$51-60$ & 10 & 5.2 \\
$61-70$ & 12 & 6.2 \\
$71-80$ & 1 & 0.5 \\
\hline$Z 5, Z 7 n$
\end{tabular}

ZS, Zinner syndrome. ultrasonography $(139 / 214,65 \%)$, computed tomography (CT) $(130 / 214,60.7 \%)$, urography $(41 / 214,19.2 \%)$, and digital rectal examination (DRE) (40/214, 18.7\%).

Although radiology was most commonly used for the diagnostic examination, cystoscopy $(30 / 214,14.0 \%)$ and transrectal ultrasonography (TRUS) $(29 / 214,13.6 \%)$ were used to obtain additional information. Diagnostic methods such as retrograde pyelography $(7 / 214,3.3 \%)(8-14)$, radioactive nephrography $(5 / 214,2.3 \%)(9,15-18)$, positron emission tomography-computed tomography (PET-CT) $(2 / 214,0.9 \%)(19,20)$, and digital subtraction angiography (DSA) $(2 / 214,0.9 \%)(21,22)$ were effective in special situations.

\section{Effects on urinary and reproductive function}

When a seminal vesicle cyst compresses vital structures, maximum flow rate, as measured by uroflowmetry, may be attenuated. Uroflowmetry was performed in 10 cases. The maximum flow rate was $3.1(18)$ to $16(23) \mathrm{m} / \mathrm{s}$, with median and standard deviation of 10.4 and $4.2 \mathrm{~m} / \mathrm{s}$, respectively. The normal reference range for maximum flow rate is $\geq 15 \mathrm{~m} / \mathrm{s}$.

Ejaculate volume was measured in 12 patients. Values

Table 2 Summary of symptoms in $173 \mathrm{ZS}$ patients

\begin{tabular}{|c|c|c|c|c|c|c|c|}
\hline \multicolumn{2}{|c|}{ Urinary symptoms } & \multicolumn{2}{|l|}{ Local pain } & \multicolumn{2}{|c|}{ Abnormal of reproductive function } & \multicolumn{2}{|l|}{ Other symptoms } \\
\hline Symptoms & Number & Symptoms & Number & Symptoms & Number & Symptoms & Number \\
\hline Dysuria & 45 & Abdominal pain & 25 & Ejaculation pain & 19 & Fever & 6 \\
\hline Urgent & 24 & Pelvic pain & 12 & Hematospermia & 15 & Defecation pain & 2 \\
\hline Hematuresis & 13 & Backache & 6 & Ejaculation weakness & 5 & Nausea and vomiting & 2 \\
\hline Nocturia & 3 & Inguinodynia & 5 & Less or no semen & 5 & Diarrhea & 1 \\
\hline \multirow[t]{4}{*}{$\begin{array}{l}\text { Urinary } \\
\text { Incontinence }\end{array}$} & 2 & Testicular pain & 3 & Sexual discomfort & 4 & $\begin{array}{l}\text { Gastrointestinal } \\
\text { uncomfortable }\end{array}$ & 1 \\
\hline & & & & & & Abdominal distension & 1 \\
\hline & & & & & & Night sweats & 1 \\
\hline & & & & & & Malaise & 1 \\
\hline
\end{tabular}

ZS, Zinner syndrome. 


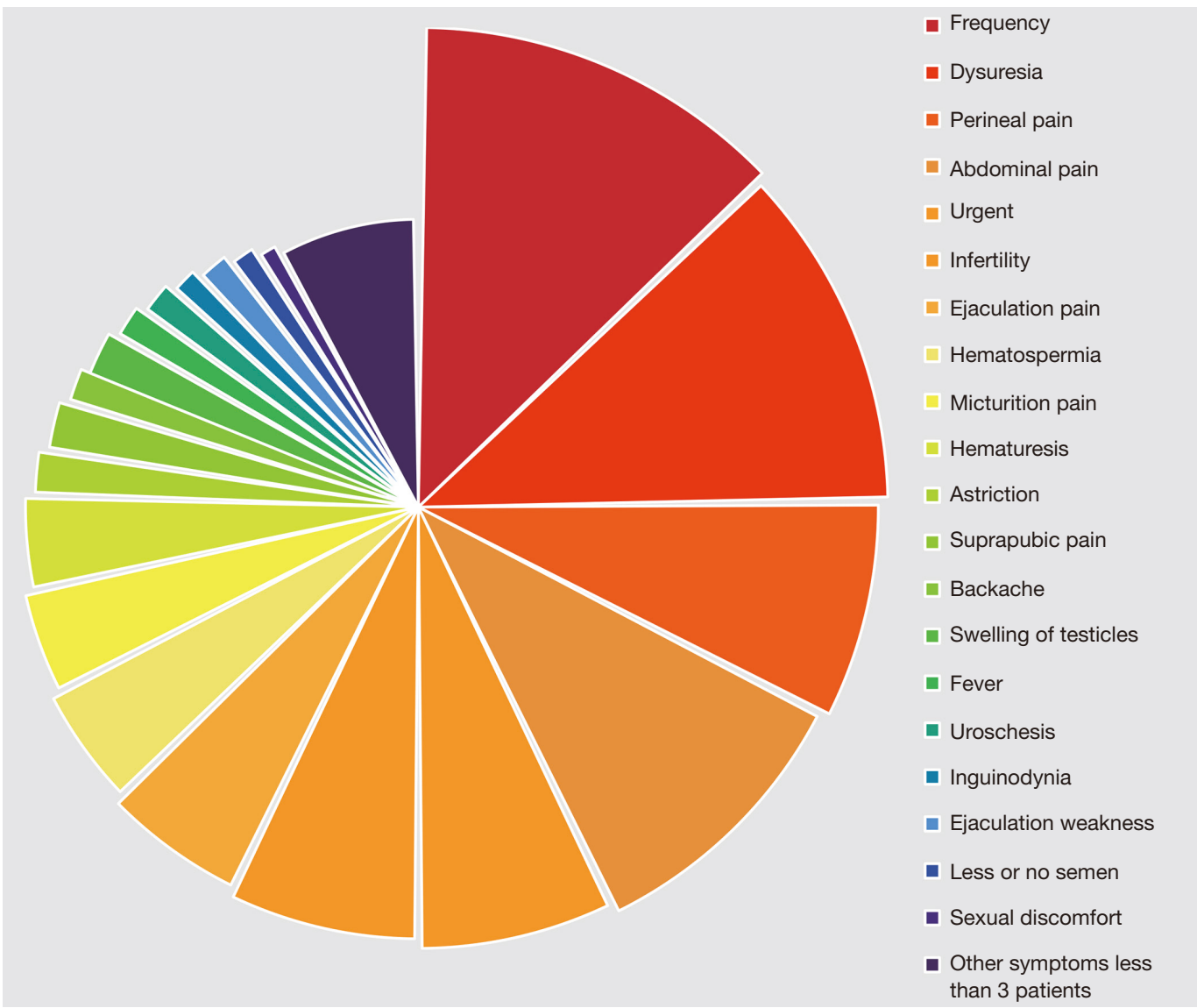

Figure 3 The frequency of various symptoms in 173 ZS patients. ZS, Zinner syndrome.

ranged from 0.1 (24) to $2.2(25) \mathrm{mL}$, with median and standard deviation of 1 and 0.6 , respectively. The normal reference range for ejaculate volume is $2-6 \mathrm{~mL}$. Details relating to sperm count were available for 7 patients. Among the patients included in this study, sperm count ranged from 160,000 (26) to $11,000,000$ (27), with median and standard deviation of 1,200,000 and 5,200,000, respectively. The normal reference range for sperm count is $>20,000,000$. Data on sperm motility were available for 7 patients. The percentage of non-motile sperm in a given patient ranged from $59.5 \%$ (28) to $100 \%$ (24), with median and standard deviation of $90 \%$ and $18.35 \%$, respectively. In an additional 12 cases, patients had were reported to have azoospermatism and oligospermia, but details were not provided.

\section{Treatment and management}

Some of the cases included in this study did not describe treatment. Details related to treatment and management were available for 193 patients (Table 4). Surgery, which was the most common approach to treatment, was performed in 127 cases $(65.8 \%, 127 / 193)$, including 39 patients who underwent open surgery, 23 patients who underwent laparoscopic surgery, 23 patients who underwent robotassisted laparoscopic vesiculectomy, five patients who underwent seminal vesiculoscopy, four patients who underwent transurethral resection of the ejaculatory duct, one patient who underwent ultrasound-guided transrectal biopsy, one patient who underwent interventional surgery, one patient who underwent cystoscopy and aspiration of the cyst, one patient who underwent transurethral unroofing of the cyst, and 29 patients who underwent surgery, with no details provided. In one case, death was caused by the metastasis of a papillary adenocarcinoma in the seminal vesicle after radical cystoprostatectomy (24). In another case, death was caused by multiple organ failure related to renaltype clear cell carcinoma in the prostate after surgery (29). 
Table 3 Summary of diagnostic examination results for 214 ZS patients

\begin{tabular}{lcc}
\hline Diagnostic examinations & N & $\begin{array}{c}\text { The percentage of choice } \\
\text { in 214 patients (\%) }\end{array}$ \\
\hline MRI & 145 & 67.8 \\
Trans-abdominal ultrasound & 139 & 65.0 \\
CT & 130 & 60.7 \\
Urography & 41 & 19.2 \\
DRE & 40 & 18.7 \\
cystoscopy & 30 & 14.0 \\
TRUS & 29 & 13.6 \\
Retrograde pyelography & 7 & 3.3 \\
Radioactive nephrogram & 3 & 1.4 \\
PET-CT & 2 & 0.9 \\
99mTc-DMSA & 2 & 0.9 \\
DSA & 2 & 0.9 \\
\hline
\end{tabular}

ZS, Zinner syndrome; MRI, magnetic resonance imaging; $\mathrm{CT}$, computed tomography; DRE, digital rectal examination; TRUS, transrectal ultrasonography; PET-CT, positron emission tomography-computed tomography; DSA, digital subtraction angiography.

The other patients who underwent surgery did not experience symptom recurrence or other complications.

With regard to invasive procedures, 19 patients (19/193, $9.8 \%$ ) underwent aspiration and drainage; 18 patients underwent transrectal aspiration of the cyst, and one patient underwent percutaneous drainage under ultrasound guidance. Nine patients $(9 / 19,47.4 \%)$ had cyst recurrence requiring surgical treatment, and one patient died of sepsis caused by an infection of the seminal vesicle cyst (30).

Forty-seven patients elected to receive conservative treatment and follow-up because of a lack of symptoms, the presence of only minor symptoms, or personal reasons $(24.2 \%, 47 / 193)$. The range of follow-up time ranged from 3 months to 15 years. During follow-up, an increase in seminal vesicle cyst size necessitated surgery in 2 cases $(31,32)$. Vasectomy was performed in one infant for recurrent epididymitis and orchitis. Nephrectomy was performed in three infants for unilateral multicystic dysplastic kidney. Kidney transplantation was performed in three infants for the treatment of bilateral dysplastic kidney (6).

\section{Complications and comorbidities}

In most cases, ZS is associated with a good prognosis. However, among the cases included in this study, 52 patients had complications or comorbidities, and three died (Table 5 , Figure 4). According to the definitions of complications and comorbidities, as well as reviews of the literature and discussions with urologists and radiologists, we treated urogenital infection and inflammation as complications and treated tumors, developmental deformities, and other diseases as comorbidities. The urogenital infection and inflammation in collection cases including urinary infection (13 patients), epididymitis (6 patients) $(6,33-37)$, prostatitis (2 patients) $(38,39)$, orchitis (2 patients) $(6,13)$, bladder infection (1 patient) (6), and sepsis caused by an infection of the seminal vesicle cysts, resulting in death (1 patient) (30). The most common comorbidities were the development of tumors, including adenoma or adenocarcinoma (40-45) arising from the seminal vesicle cyst (6 patients), paraganglioma affecting the bladder in 1 patient and affecting paranephrotic tissue in another patient $(46,47)$, squamous cell carcinoma arising from the seminal vesicle (1 patient) (48), non-hodgkin lymphoma (1 patient) (19), and renal-type clear cell carcinoma affecting the prostate (1 patient) (43). Two patients with adenocarcinoma associated with a seminal vesicle cyst died because of metastasis and multiple organ failure. ZS may also be combined with other developmental deformities, including cryptorchidism (2 patients) $(49,50)$, anorectal malformation (2 patients), contralateral dysplastic kidney (2 patients), ventricle septum defect (2 patients) (6), situs inversus viscerum (1 patient) (51), mitral insufficiency (1 patient) (52), and multiple severe developmental deformities (1 patient) (53). Comorbidities caused by unrelated illness or syndromes were relatively rare. In this study, 3 patients had complications related to Kallmann syndrome (21,54-56), 1 patient had complications related to thalassemia, and 1 patient had complications related to Fabry disease (57).

\section{Discussion}

$\mathrm{ZS}$ is a rare condition. The constellation of associated congenital findings includes ipsilateral renal hypoplasia, cystic seminal vesicles, and ejaculator duct obstruction. It occurs with anomalous growth of the mesonephric or 
Table 4 Summary of management in 193 ZS cases

\begin{tabular}{llll}
\hline Management measures & $\mathrm{N}$ & $\%$ & Prognosis \\
\hline Open operation & 39 & 20.2 & 1 patient dead \\
Surgical operation no details & 29 & 15.0 & 1 patient dead \\
Laparoscopic surgery & 23 & 11.9 & Favorable \\
Robotic-assisted laparoscopic vesiculectomy & 23 & 11.9 & Favorable \\
Seminal vesiculoscopy & 5 & 2.6 & Favorable \\
Transuretral resection of the ejaculatory duct & 4 & 2.1 & Favorable \\
Ultrasound-guided transrectal biopsy & 1 & 0.5 & Favorable \\
Interventional operation & 1 & 0.5 & Favorable \\
Cystoscope and aspiration of the cyst & 1 & 0.5 & Favorable \\
Transurethral unroofing of the cyst & 1 & 0.5 & Favorable \\
Aspiration and drainage & 19 & 9.8 & 9 patients recurrence \& 1 patient dead \\
Follow up & 47 & 24.3 & 9 patients (included 7 infants) need surgery \\
Total & 193 & 100.0 & \\
\hline
\end{tabular}

ZS, Zinner syndrome.

Wolffian duct between 4 and 13 weeks of gestation and negatively impacts embryological development of the kidney and ejaculatory duct.

A pooled analysis was published by van den Ouden et al. in 1998. We sought to provide an updated review to help clinicians. Most patients with ZS present during the second or third decade of life. Compared with the study published by van den Ouden et al., our study had a greater sample size. We found that there was no obvious difference in the incidence of left-sided $v s$. right-sided disease. This finding differs from those reported by van den Ouden et al. The most common symptoms among our patient population were dysuria, perineal pain, urinary frequency, and urinary urgency. These symptoms may be associated with an increase in cyst size. On the other hand, some patients had impaired reproductive function, including 12 patients presented with low-volume ejaculation, seven patients had low sperm motility, and 19 patients presented with azoospermatism and oligospermia. Decreases in sperm count may be related to obliteration of the ejaculatory duct, the hemorrhage of seminal vesicle cysts, or secondary inflammation of the genitourinary system.

We also found that the choice of diagnostic examination had important effects on the selection of radiological techniques. In 1998, DRE and intravenous urography were commonly used for the diagnosis of ZS. In contrast, the studies included in this review used MRI, transabdominal ultrasound, and CT because of these techniques' noninvasive nature and ease of use. MRI was recommended by radiologists to differentiate between lesions and surrounding normal tissue as well as the effects of nonionizing radiation. Recent developments in the field of MRI have led to improved field intensity and new sequences, which provide more information about the condition of underdeveloped kidneys and ureters, cyst contents, and surrounding tissue or organs affected by complications. This information is helpful for guiding the clinical decision. In this review, seminal vesicle cyst and ipsilateral renal agenesis were first detected by trans-abdominal ultrasound because of its convenience for screening. CT is an important supplement for patients with contraindications for MRI. The information obtained via CT and urography can supplement other information such as the extent of calcification and urinary function.

In the studies included in this review, surgery (open or laparoscopic) was the most effective treatment and postoperative recurrence was rare. As new methods of surgery that were not mentioned in the study by van den Ouden et al., endoscopy and robot-assisted technology have become increasingly popular among physicians performing seminal vesiculectomy since 2002 (58) and 2007 (59), respectively. Compared with open seminal vesiculectomy, 
Table 5 Complications and comorbidities in $52 \mathrm{ZS}$ patients

\begin{tabular}{|c|c|c|}
\hline Complications and comorbidities & $\mathrm{N}$ & $\begin{array}{c}\text { The percentage } \\
\text { in } 214 \text { patients } \\
\text { (\%) }\end{array}$ \\
\hline Tumors & 11 & \\
\hline Adenocarcinoma (seminal vesicle) & 5 & 2.34 \\
\hline Adenoma & 1 & 0.47 \\
\hline Paraganglioma (bladder and aranephros) & 2 & 0.93 \\
\hline Squamous cell carcinoma (seminal vesicle) & 1 & 0.47 \\
\hline Non-Hodgkin lymphoma (lymphoid tissue) & 1 & 0.47 \\
\hline Renal-type clear cell carcinoma (prostate) & 1 & 0.47 \\
\hline Developmental deformities & 10 & \\
\hline Situs inversus viscerum & 1 & 0.47 \\
\hline Mitral insufficiency & 1 & 0.47 \\
\hline Cryptorchidism & 2 & 0.93 \\
\hline Anorectal malformation & 2 & 0.93 \\
\hline Contralateral dysplastic kidney & 2 & 0.93 \\
\hline Ventricle septum defect & 2 & 0.93 \\
\hline Multiple developmental deformity & 1 & 0.47 \\
\hline Infections or inflammations & 25 & \\
\hline Urinary infection & 13 & 6.07 \\
\hline Bladder infection & 1 & 0.47 \\
\hline Epididymitis & 6 & 2.80 \\
\hline Prostatitis & 2 & 0.93 \\
\hline Orchitis & 2 & 0.93 \\
\hline Sepsis & 1 & 0.47 \\
\hline Other illness or syndromes & 5 & \\
\hline Kallmann syndrome & 3 & 1.40 \\
\hline Thalassemia & 1 & 0.47 \\
\hline Fabry disease & 1 & 0.47 \\
\hline Total number of patients & 52 & 23.83 \\
\hline
\end{tabular}

ZS, Zinner syndrome.

laparoscopic and robot-assisted seminal vesiculectomy are safer, less invasive, accompanied by less bleeding, and associated with quicker recover. Among the 46 patients included in this review who underwent laparoscopic (23 patients) or robot-assisted seminal vesiculectomy (23 patients), prognosis was favorable, with no postoperative complications reported. However, our sample size was insufficient to demonstrate the safety of surgical treatment for ZS. A large-scale of meta-analysis (60) that included more than 200,000 patients indicated that open retropubic radical prostatectomy (ORP), laparoscopic radical prostatectomy (LRP), and robot-assisted laparoscopic radical prostatectomy (RALP) were associated with high risk for surgical complications leading to erectile dysfunction (ORP: 42.7-61.8\%; LRP: 45-71.1\%; RALP: 23.4-68.2\%) and urinary incontinence (ORP: 15.4-28\%; LRP: 7.142.8\%; RALP: 7.7-20.7\%). Although the target organs are different, the surgical methods, surgical approaches, and surrounding tissues are similar between prostatectomy and seminal vesicle resection, seminal vesicle resection still carries risk for surgical complications. Postoperative recurrence was not found in the van den Ouden et al. (1) report or our population, but that does not mean that it is impossible. Additional cases and longer follow-up time are necessary.

Another option in such cases is aspiration and drainage. van den Ouden et al. reported that the rate of success after aspiration was $30 \%$, and $47.4 \%$ of patients included in the present review who underwent aspiration had symptom recurrence. As a variety of invasive treatment, aspiration was unable to decrease the risk for seminal vesicle cyst recurrence, so it is not valuable as a management strategy. Asymptomatic patients should be followed with observation, but when symptoms appear, clinical intervention is needed.

The complications and comorbidities experienced by ZS patients deserve attention but have been neglected in the past. In this review, three patients died because of complications or comorbidities. Secondary inflammation and ZS-related are the frequent complications in this patient population. These complications present with symptoms, so they should not easily be overlooked. However, tumor as comorbidity may not present with any specific symptoms in the early stage. In our review, tumors occurred in 10 patients $(4.4 \%)$, and two patients died because of multiple metastases or organ failure. Patients with ZS and tumors arising from the urogenital system [including adenocarcinoma of the seminal vesicle $(5,2.34 \%)$, clear cell renal carcinoma of the prostate $(1,0.47 \%)$, paraganglioma $(2,0.93 \%)$ and squamous cell carcinoma of the seminal vesicle $(1,0.47 \%)]$ are rare conditions in ordinary people. According to the relatively high incidence of disease in this ZS population, although the exact reason remains unknown, ZS may be a positive stimulating factor for urogenital system tumors. Other developmental abnormalities or diseases can occur, but they are relatively rare. Remarkably, 


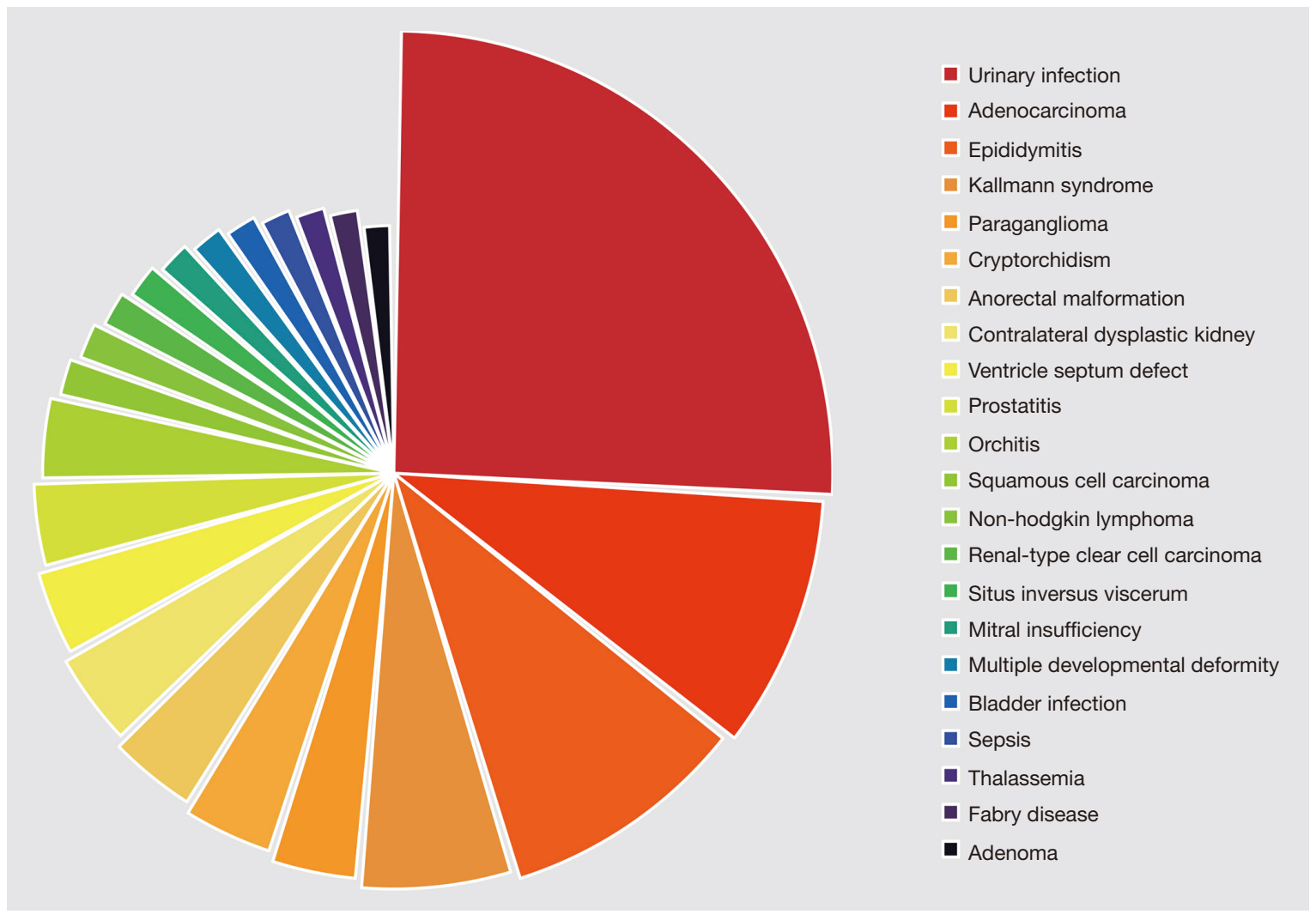

Figure 4 The frequency of complications and comorbidities in 52 ZS patients. ZS, Zinner syndrome.

three ZS patients included in this review had Kallmann syndrome, which was more common than cryptorchidism and contralateral dysplastic kidney. We consider that ZS and Kallmann syndrome may have some kind of relationship, but the cases and data were not sufficient for investigation.

This review has several limitations. First, it was not possible to classify patients by ethnicity because the information was lacking from many studies. Only 13 patients could be classified according to ethnicity: 7 Caucasian males; 2 Saudi Arabian males; 1 Indian male; 1 Hispanic male; 1 Moroccan male; 1 Italian male. Second, it was not possible to classify seminal vesicle lesions based on wall changes because the information was lacking from many studies. Third, there may have been some publication bias, resulting in overestimations of the proportions of symptoms, complications, and comorbidities. Fourth, a majority of cases lack relevant information such as uroflowmetry, semen ejaculate volume, sperm count, and sperm motility, so it difficult to provide convincing data on the effect of ZS on male reproductive function. Finally, some of the studies and conference papers identified by our initial literature search provided only abstracts. We had to exclude these publications from our review. In conclusion, the clinical symptoms associated with ZS syndrome are varied, but the most common symptoms are enlargement of seminal vesicle cysts and compression of the bladder, ureters, and reproductive system, as well as associated secondary lesions. The diagnosis mostly depends on the results of radiological examinations. Complications and comorbidities should be identified, with treatment tailored accordingly.

\section{Acknowledgments}

Funding: None.

\section{Footnote}

Reporting Checklist: The authors have completed the PRISMA reporting checklist. Available at http://dx.doi. org/10.21037/apm-20-1997

Conflicts of Interest: All authors have completed the ICMJE 
uniform disclosure form (available at http://dx.doi. org/10.21037/apm-20-1997). The authors have no conflicts of interest to declare.

Ethical Statement: The authors are accountable for all aspects of the work in ensuring that questions related to the accuracy or integrity of any part of the work are appropriately investigated and resolved.

Open Access Statement: This is an Open Access article distributed in accordance with the Creative Commons Attribution-NonCommercial-NoDerivs 4.0 International License (CC BY-NC-ND 4.0), which permits the noncommercial replication and distribution of the article with the strict proviso that no changes or edits are made and the original work is properly cited (including links to both the formal publication through the relevant DOI and the license). See: https://creativecommons.org/licenses/by-nc-nd/4.0/.

\section{References}

1. van den Ouden D, Blom JH, Bangma C, et al. Diagnosis and management of seminal vesicle cysts associated with ipsilateral renal agenesis: a pooled analysis of 52 cases. Eur Urol 1998;33:433-40.

2. Sheih CP, Hung CS, Wei CF, et al. Cystic dilatations within the pelvis in patients with ipsilateral renal agenesis or dysplasia. J Urol 1990;144:324-7.

3. Zhu N, Zhang D, Wang W, et al. A Novel Coronavirus from Patients with Pneumonia in China, 2019. N Engl J Med 2020;382:727-33.

4. Pace G, Galatioto GP, Gualà L, et al. Ejaculatory duct obstruction caused by a right giant seminal vesicle with an ipsilateral upper urinary tract agenesia: an embryologic malformation. Fertil Steril 2008;89:390-4.

5. Jiang XS, Wang HJ, Lin JH, et al. Zinner's syndrome: clinical features and imaging diagnosis. Asian J Androl 2018;20:316-7.

6. Schukfeh N, Kuebler JF, Schirg E, et al. Dysplastic kidney and not renal agenesis is the commonly associated anomaly in infants with seminal vesicle cyst. BJU Int 2009;103:816-9.

7. Fujita M, Goto T, Saiki S. Seminal vesicle cyst associated with ipsilateral renal dysplasia and vena cava malformation: a case report. Hinyokika Kiyo 2012;58:511-4.

8. Burns JA, Cooper CS, Austin JC. Cystic dysplasia of the testis associated with ipsilateral renal agenesis and contralateral crossed ectopia. Urology 2002;60:344.

9. Sukumar S, Khanna V, Nair B, et al. Adult presentation of congenital ectopic vas deferens insertion into ureter with unilateral renal agenesis. Surg Radiol Anat 2010;32:9-10.

10. Nayak B, Abrol N, Kumar R. Radiological seminal vesicle stones may actually be in the ureter. Indian J Urol 2013;29:75-6.

11. Haddock P, Wagner JR. Seminal vesicle cyst with ipsilateral renal agenesis and ectopic ureter (Zinner syndrome). Urology 2015;85:e41-2.

12. Sundar R, Sundar G. Zinner syndrome: an uncommon cause of painful ejaculation. BMJ Case Rep 2015;2015:bcr2014207618.

13. Cascini V, Di Renzo D, Guerriero V, et al. Zinner syndrome in pediatric age: issues in the diagnosis and treatment of a rare malformation complex. Front Pediatr 2019;7:129.

14. Maré A, Liddell H, Chan HF. Ectopic megaureter inserting into seminal vesicle cyst with fistula to bladder. ANZ J Surg 2017;87:E90-1.

15. Chuang KL, Lai WI, Chiang YJ. Giant seminal vesicle cyst resembling megaureter with hydronephrosis. Arch Androl 2005;51:367-9.

16. Ulu EMK, Başaran C, Dönmez FY, et al. Mullerian duct cyst with ipsilateral renal agenesis: MRI findings. Marmara Medical Journal 2009;22:64-7.

17. Jaiswal A, Francis SK, Tuli A, et al. Zinner syndrome: rare cause of urinary symptoms in young adult male. Indian J Urol 2016.

18. Maehana T, Fukuta F, Kobayashi K, et al. Laparoscopic surgery for seminal vesicle cysts and ureterocele with urination disorder: a case report of Zinner syndrome. J Endourol Case Rep 2018;4:35-8.

19. Kuo J, Foster C, Shelton DK. Zinner's syndrome. World J Nucl Med 2011;10:20-2.

20. Harbo FS, Larsen LB. Seminal vesicle cyst with ipsilateral renal agenesis. Ugeskr Laeger 2015;177:104-5.

21. Savica V, Santoro D, Monardo P, et al. Seminal vesicle cysts with unilateral renal agenesis and contralateral ureteral stenosis in a $\beta$-thalassemic patient: an unknown association by incomplete development of the mesonephric duct. Urol Int 2007;79:367-70.

22. Royston E, Walker M, Ching B, et al. Postcoital hemorrhage of a recurrent seminal vesicle cyst requiring embolization. Urol Case Rep 2014;2:171-2.

23. Kiremit MC, Acar O, Sag AA, et al. Minimally invasive management of Zinner's syndrome with same-session robot-assisted seminal vesiculectomy and ipsilateral nephroureterectomy using a single geometry of trocars. J Endourol Case Rep 2018;4:186-9. 
24. Kawahara T, Nishiyama H, Okubo K, et al. Right ectopic ureter with ipsilateral renal agenesis presenting with infertility: a case report. Hinyokika Kiyo 2004;50:435-8.

25. Andrade-Rocha FT. Semen analysis in an infertile man with seminal vesicles cysts associated with ipsilateral renal agenesis. Int Urol Nephrol 2006;38:101-3.

26. Calahorra Fernández FJ, García Cardoso JV, Montero Rubio R, et al. Quiste gigante de vesícula seminal asociado con agenesia renal ipsilateral. Actas Urol Esp 2002;26:218-23.

27. Mehra S, Ranjan R, Garga UC. Zinner syndrome-a rare developmental anomaly of the mesonephric duct diagnosed on magnetic resonance imaging. Radiol Case Rep 2016;11:313-7.

28. Kao CC, Wu CJ, Sun GH, et al. Congenital seminal vesicle cyst associated with ipsilateral renal agenesis mimicking bladder outlet obstruction: a case report and review of the literature. Kaohsiung J Med Sci 2010;26:30-4.

29. Sato Y, Kataoka M, Hata J, et al. Renal-type clear cell carcinoma occurring in the prostate with Zinner syndrome. Urol Case Rep 2016;5:9-12.

30. Chung SD, Sun HD, Chiu CY. Lethal infected seminal vesicle cyst. Int J Infect Dis 2009;13:e197-8.

31. te Dorsthorst MJ, Prins-van Uden M, Niekel R, et al. Case report. Zinner-syndroom: een zeldzame oorzaak van agenesie van de nier. Tijdschrift voor Urologie 2020;10:9-12.

32. Alhajeri F, Salem S, Harraz A, et al. Scientific Program of 37 th World Congress of Endourology Program Book. J Endourol 2019;33.

33. Giglio M, Medica M, Germinale F, et al. Renal dysplasia associated with ureteral ectopia and ipsilateral seminal vesicle cyst. Int J Urol 2002;9:63-6.

34. Liatsikos EN, Lee B, Filos KS, et al. Congenital seminal vesicle cyst and coexisting renal agenesis: laparoscopic approach. Urology 2004;63:584-6.

35. Berg F, Ohlmann C, Gossmann A. MR tomographic diagnosis of a congenital seminal cyst in ipsilateral renal agenesis with ureterocele as rare differential diagnosis of prostatic tumor. Rofo 2005;177:1308-9.

36. Heller MT, Hartman M, McGreevy B. Seminal vesicle cysts causing pelvic pain: importance of computed tomography. Am J Emerg Med 2012;30:2087.e1-6.

37. Herrero Blanco E, Campos-Juanatey F, Lastra GarcíaBarón P, et al. Zinner`s syndrome in a polytrauma patient. Arch Esp Urol 2019;72:608-11.

38. McAdams S, Schomburg J, Sweet RM. Zinner's syndrome. Like sitting on a tennis ball for 20 years. Minn Med
2014;97:40-1.

39. Sigüenza González R, Sánchez Lite I. Seminal vesicle cyst: An isolated finding? Radiologia 2018;60:446-8.

40. Kluckert JT, Zaunbauer W, Diener PA. Congenial seminal vesicle cyst with an intracystic papillary adenoma associated with ipsilateral renal agenesis. Radiologe 2002;42:837-9.

41. Kondo N, Shiono Y, Yoshino Y, et al. Papillary adenocarcinoma in a seminal vesicle cyst associated with contralateral renal agenesis: a case report. Hinyokika Kiyo 2007;53:175-8.

42. Lee BH, Seo JW, Han YH, et al. Primary mucinous adenocarcinoma of a seminal vesicle cyst associated with ectopic ureter and ipsilateral renal agenesis: a case report. Korean J Radiol 2007;8:258-61.

43. Satyanarayana R, Katkoori D, Young E, et al. Robotic assisted excision of a giant seminal vesicle cyst and atretic ureter. J Endourol 2013;27:A443.

44. Deptala A, Romanowicz A, Czerw A, et al. Congenital anomalies of the genitourinary system can help in diagnosis of the primary site of metastatic cancer: a case report and a review of the literature. Onco Targets Ther 2016;9:4435-40.

45. Bhat A, Banerjee I, Kryvenko ON, et al. Primary seminal vesicle adenocarcinoma: a lethal yet cryptic malignancy with review of literature. BMJ Case Rep 2019;12:e232994.

46. Valsangkar RS, Goyal NK, Bajania SP, et al. Bladder paraganglioma with renal agenesis: A possible new association and its implications in the light of rearranged in transfection gene genetics. Urol Ann 2015;7:410-3

47. Ali MS, Dubey D, Dias B. Robotic Assisted excision of extra adrenal Paraganglioma presenting as left seminal vesicle mass. Indian J Urol 2018;34:37.

48. Kim YH, Moon KC. Zinner Syndrome patient with squamous cell carcinoma arising from squamous metaplasia of the seminal vesicle: a case report. Virchows Archiv 2014;465:S165.

49. Yu YD, Hong YK. A case of cryptorchidism with ipsilateral congenital unilateral absence of the vas deferens and contralateral renal agenesis. Case Rep Urol 2016;2016:2379793.

50. Naval-Baudin P, Carreño García E, Sanchez Marquez A, et al. Multicystic seminal vesicle with ipsilateral renal agenesis: two cases of Zinner syndrome. Scand J Urol 2017;51:81-4.

51. Fiaschetti V, Greco L, Giuric, et al. Zinner syndrome diagnosed by magnetic resonance imaging and computed tomography: role of imaging to identify and evaluate the 
uncommon variation in development of the male genital tract. Radiol Case Rep 2016;12:54-8.

52. Kowalczyk K, Baka-Ostrowska M, Felberg K, et al. Unilateral renal dysplasia associated with ectopic ureter opening into ipsilateral ejaculatory duct. Cent European J Urol 2009;62:181-2.

53. Lilje C, Finger LJ, Ascuitto RJ. Complete unilateral leg duplication with ipsilateral renal agenesis. Acta Paediatr 2007;96:464-5.

54. Sridhar AN, Zacharakis E, Dudderidge T, et al. Robotassisted management of Zinner's syndrome: report of seminal vesicle sparing technique and review of literature. J Robot Surg 2014;8:185-7.

55. Domínguez A, Abascal-Junquera JM, Muñoz-Rodríguez J, et al. Síndrome de Zinner en paciente afecto de síndrome de Kallmann: rara asociacion de 2 malformaciones embrionarias. Revista Internacional de Andrología 2016;14:144-7.

Cite this article as: Liu T, Li X, Huang L, Li H, Cai K, Jiang J, Chen N, Zhang W, Tang J, Zhang M, Zhao D, Ye J, Zhang C, He T, Liu B, Ye Y, Chen J. Zinner syndrome: an updated pooled analysis based on 214 cases from 1999 to 2020: systematic review. Ann Palliat Med 2021;10(2):2271-2282 . doi: 10.21037/apm20-1997
56. Leen A, Dirk V. Zinner's syndrome in a patient with X-linked Kallmann syndrome: case report. Acta Clin Belg 2016;71:6.

57. Sousa C, Teixeira IP, Ferreira SH, et al. Zinner's syndrome: case report of a rare maldevelopment in the male genitourinary tract. Journal of Urological Surgery 2019;6:65.

58. Buogo G, Rodrigues H, Rodrigues P. Laparoscopic removal of seminal vesicle cyst with ectopic ureteral insertion and renal remnant. Int Braz J Urol 2002;28:335-7.

59. Moore CD, Erhard MJ, Dahm P. Robot-assisted excision of seminal vesicle cyst associated with ipsilateral renal agenesis. J Endourol 2007;21:776-9.

60. Basiri A, de la Rosette JJ, Tabatabaei S, et al. Comparison of retropubic, laparoscopic and robotic radical prostatectomy: who is the winner? World J Urol 2018;36:609-21. 


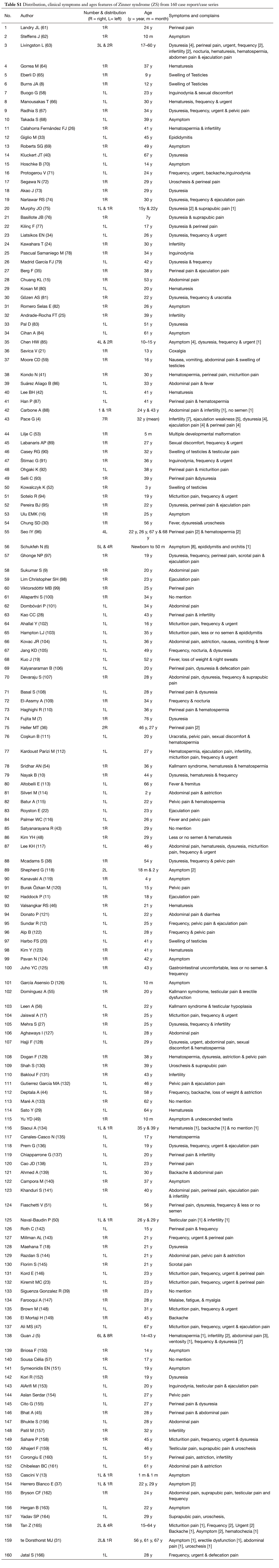


61. Landry JL, Dodat H, Pelizzo G, et al. Cystic dysplasia of the rete testis and ipsilateral kidney agenesis in children. Arch Pediatr 1999;6:416-20

62. Steffens J, Oberschulte-Beckmann D, Siller V, et al. Ectopic refluxing ureter entering a seminal vesicle cyst associated with ipsilateral renal dysplasia. World J Urol 2000;18:232-4.

63. Livingston L, Larsen CR. Seminal vesicle cyst with ipsilateral renal agenesis. AJR Am J Roentgenol 2000;175:177-80.

64. Gorrea M, Lorente R, Roel J. Seminal vesicle cyst associated with ipsilateral renal agenesis and papillary carcinoma of the bladder. Eur Radiol 2001;11:2500-3.

65. Eberli D, Gretener H, Dommann-Scherrer C, et al. Cystic dysplasia of the testis: a very rare paediatric tumor of the testis. Urol Int 2002;69:1-6.

66. Manousakas T, Kyriakou G, Serafetinides E, et al. Partial vesiculectomy in an infertile man with seminal vesicle cyst, ipsilateral renal agenesis, and cryptorchidism. Urology 2002;59:602.

67. Radhia S, Samira F, Mounir T, et al. Kyste de la vésicule séminale associé à une agénésie rénale et à un uretère ectopique ipsilatéral. À propos d'un cas. Annales d'Urologie 2002;36:381-3.

68. Takada S, Noda Y, Oka T, et al. Seminal vesicle cyst associated with ipsilateral renal dysplasia: a case report. Nishinihon Journal of Urology 2002;64:436-9.

69. Roberts SG, Garcia Mediero JM, Segura JW, et al. Incidental pelvic mass identified during ultrasound-guided transrecta needle biopsy of the prostate. Arch Esp Urol 2002;55:466-8.

70. Hoschke B, May M, Seehafer M, et al. Outlet of a megaureter with aplastic kidney into a seminal vesicle cyst. Case report of laparoscopic intervention. Urologe A 2003;42:1092-6.

71. Protogerou V, Chorti M, Kostakopoulos A. Congenital dilation of seminal vesicle with agenesis of ipsilateral kidney: symptoms and treatment. Int Urol Nephrol 2003;35:69-71.

72. Segawa N, Gohji K, Masuda H, et al. A case of CA19-9-producing seminal vesicle cyst with ipsilateral renal agenesis. Hinyokika Kiyo 2003;49:277-80.

73. Akao J, Arikawa M, Aramaki K, et al. Seminal vesicle cyst associated with ipsilateral renal dysplasia: a case report. Nishinihon Journal of Urology 2003;65:505-8.

74. Narlawar RS, Hanchate V, Raut A, et al. Renal agenesis and seminal vesicle cyst. J Ultrasound Med 2003;22:225-8.

75. Murphy JO, Power RE, Akhtar M, et al. Magnetic resonance imaging in the diagnosis of seminal vesicle cysts and associated anomalies. J Urol 2003;170:2386.

76. Basillote JB, Shanberg AM, Woo D, et al. Laparoscopic excision of a seminal vesicle cyst in a child. J Urol 2004;171:369-71

77. Kilinç F, Güvel S, Eğilmez T, et al. Seminal vesicle cyst, ectopic ureter opening into the cyst and ipsilateral renal agenesis. Turk Uroloji Dergisi 2004;30:369-71.

78. Pascual Samaniego M, Egea Camacho J, Cortiñas González JR, et al. Agenesia renal derecha y abocamiento ectópico del uréter en dilatación quística de la vesícula seminal. Actas Urológicas Españolas 2004;28:688-93.

79. Madrid García FJ, Madroñero Cuevas C, Rivas Escudero JA, et al. Seminal vesicle cyst and ipsilateral renal agenesis. Arch Esp Urol 2004;57:168-71.

80. Kosan M, Tul M, Inal G, et al. A large seminal vesicle cyst with contralateral renal agenesis. Int Urol Nephrol 2006;38:591-2

81. Gözen AS, Alagöl B. Endoscopic management of seminal-vesical cyst with right renal agenesis causing acute urinary retention: case report. J Endourol 2006;20:919-22.

82. Romero Selas E, Montes M, Barbagelata A, et al. Seminal vesicle cyst and ipsilateral renal agenesis. Arch Esp Urol 2006:59:750.

83. Pal D, Bag A, Sarkar S. Giant seminal vesicle cyst with ipsilateral hypoplastic kidney: Report of a case with review of literature. Indian J Urol 2006;22:64-5.

84. Cihan A, Cimen S, Secil M, et al. Congenital seminal vesicle cyst accompanying ipsilateral renal agenesis and rudimentary ureter. Int Urol Nephrol 2006;38:133-5.

85. Chen HW, Huang SC, Li YW, et al. Magnetic resonance imaging of seminal vesicle cyst associated with ipsilateral urinary anomalies. J Formos Med Assoc 2006;105:125-31.

86. Suárez Aliago B, Rodríguez Jiménez I. Seminal vesicle cyst with renal agenesis associated with vascular anomalies. Case report. Arch Esp Urol 2007;60:1.134-6

87. Han P, Dong Q, Shi M, et al. Seminal vesicle cyst and ipsilateral renal agenesis: Laparoscopic approach. Arch Androl 2007;53:285-8.

88. Carbone A, Palleschi G, Tomiselli G, et al. Renal aplastic dysplasia and ipsilateral ectopic ureter obstructing the semina via: a possible cause of male infertility. Eur Urol 2007;52:268-72.

89. Labanaris AP, Zugor V, Meyer B, et al. A case of a large seminal vesicle cyst associated with ipsilateral renal agenesis. ScientificWorldjournal 2008;8:400-4.

90. Casey RG, Stunell H, Buckley O, et al. A unique radiological pentad of mesonephric duct abnormalities in a young man presenting with testicular swelling. Br J Radiol 2008;81:e93-6.

91. Stimac G, Dimanovski J, Spaiic B, et al. Seminal vesicle cyst with ectopic ureteral insertion and ipsilateral renal dysplasia-an unexpected diagnosis. Acta Clin Croat 2008;47:101-4.

92. Ohgaki K, Horiuchi K, Oka F, et al. A case of seminal vesicle cyst associated with ipsilateral renal agenesis diagnosed during an investigation of perineal pain. J Nippon Med Sch 2008;75:122-6.

93. Selli C, Cavalleri S, De Maria M, et al. Robot-assisted removal of a large seminal vesicle cyst with ipsilateral renal agenesis associated with an ectopic ureter and a müllerian cyst of the vas deferens. Urology 2008;71:1226.e5-7.

94. Sotelo R, Herrera C, Carmona O, et al. Robot-assisted excision of a Mullerian cyst with anastomosis of the vas deferens to the seminal vesicle. J Urol 2009;74:S163-4.

95. Pereira BJ, Sousa L, Azinhais P, et al. Zinner's syndrome: an up-to-date review of the literature based on a clinical case. Andrologia 2009;41:322-30.

96. Seo IY, Kim HS, Rim JS. Congenital seminal vesicle cyst associated with ipsilateral renal agenesis. Yonsei Med J 2009;50:560-3.

97. Ghonge NP, Aggarwal B, Sahu AK. Zinner syndrome: a unique triad of mesonephric duct abnormalities as an unusual cause of urinary symptoms in late adolescence. Indian J Urol 2010;26:444-7.

98. Lim CS, Lee DF, Mackie S, et al. Seminal vesicle cyst, vas deferens ectopia, pelvic kidney and cryptorchidism. ANZ J Surg 2010;80:382.

9. Viktorsdóttir MB, Jónsson E, Einarsdóttir H. Case report: Seminal vesicle cyst with ipsilateral renal agenesis Laeknabladid 2010;96:619-20.

100. Allaparthi S, Blute RD Jr. Novel application of da Vinci robotic system in patients of Zinners syndrome--case report an review of literature. Can J Urol 2010;17:5109-13.

101. Dombóvári P, Mavrogenis S, Borka K, et al. Seminal vesicle cyst presenting as pelvic abscess. Journal of Sexual Medicine 2010;7:458.

102. Ahallal Y, Tazi MF, Khallouk A, et al. Conservative management of a congenital seminal vesicle cyst associated with ipsilateral renal agenesis revealed by cystitis: one case report. Case Rep Urol 2011;2011:125753.

103. Hampton LJ, Moore BW, Orton VA, et al. Robotic excision of a large seminal vesicle cyst: Zinners syndrome. J Endourol 2011;25:A326

104. Kovac JR, Golev D, Khan V, et al. Case of the month \# 168: seminal vesicle cysts with ipsilateral renal dysgenesis. Can Assoc Radiol J 2011;62:223-5.

105. Jang KD, Choi KH, Yang SC, et al. Laparoendoscopic single-site surgery (LESS) for excision of a seminal vesicle cyst associated with ipsilateral renal agenesis. Korean J Urol 2011;52:431-3.

106. Kalyanaraman B, Shah AK, Vemana G, et al. Seminal vesicle cyst as an unusual cause of anejaculation. J Endourol 2012;26:A223.

07. Devaraju S, Nerli RB, Hiremath MB. A large mullerian duct cyst presenting as an abdominal mass with ipsilateral renal agenesis: an unusual presentation. Nephrourol Mon 2012;4:640-3.

108. Basal S, Alp BF, Demirer Z, et al. Robot assisted laparoscopic surgery for seminal vesicle cyst. J Endourol 2012;26:A220-1.

109. El-Assmy A, Abou-El-Ghar ME. Giant seminal vesicle cyst causing ipsilateral hydronephrosis with contralateral renal agenesis. Urology 2012;79:e17-8.

110. Haghighi R, Shadpour P, Maghsudy R. Renal agenesis associated with ipsilateral ectopic ureter entering a large seminal vesicle. J Endourol 2012;26:A431.

111. Coşkun B, Dalkilıç A, Sönmez NC, et al. A case of seminal vesicle cyst associated with ipsilateral renal agenesis diagnosed during an investigation of urinary incontinence. Turk J Urol 2013;39:53-5.

112. Kardoust Parizi M, Shakhssalim N. Management of Zinner's syndrome associated with contralateral seminal vesicle hypoplasia: a case report. Case Rep Urol 2013;2013:494215.

113. Altobelli E, Bove AM, Falavolti C, et al. Robotic-assisted laparoscopic approach in the treatment for Zinner's Syndrome associated with ipsilateral megaureter and incomplete double-crossed ectopic ureter. Int Urol Nephrol 2013;45:635-8.

114. Silveri M, Zaccara A, Colajacomo M, et al. ... And if this was a Zinner's syndrome? J Pediatr Surg Case Rep 2014;2:530-2.

115. Batur A, Karakose S, Karalezli G. Congenital seminal vesicle cyst accompanying ipsilateral renal and ureteral agenesis. Urol J 2014;11:1203.

116. Palmer WC, Patel NC, Renew JR, et al. Acute infection of a documented seminal vesicle cyst via hematogenous seeding 
Urol J 2014;10:1157-9

117. Lee KH, Liao ACH, Liu CL, et al. Laparoscopic excision of a huge seminal vesicle cyst associated with ipsilateral renal agenesis. J Endourol 2014;28:A306.

118. Shepherd G, Rajimwale A. Embryology of the absent vas supported by 2 cases of congenital unilateral absence of vas with varied associations. Urol Case Rep 2014;2:49-50.

119. Kanavaki A, Vidal I, Merlini L, et al. Congenital seminal vesicle cyst and ipsilateral renal agenesis (Zinner syndrome): a rare association and its evolution from early childhood to adolescence. European J Pediatr Surg Rep 2015;3:98-102.

120. Burak Özkan M, Ceyhan Bilgici M, Şahin M, et al. Congenital seminal vesicle cyst accompanying with ipsilateral renal agenesis in an adolescent patient: a pediatric radiologist approach to Zinner's syndrome. The Egyptian Journal of Radiology and Nuclear Medicine 2015;46:1159-62.

121. Donato P, Roberts MJ, Hirst J, et al. Acute obstructive nephropathy in a solitary kidney secondary to massive seminal vesicle cyst. ANZ J Surg 2018;88:E345-7.

22. Alp B, Demirer Z, Guragac A, et al. Ipsilateral Renal Agenezinin Eslik Ettigi Dev Seminal Vezikul Kistinin Robot Yardimli Laparaskopik Cerrahi Ile Tedavisi. Gülhane Tip Derg 2015;57:331-4.

123. Kim Y, Baek HW, Choi E, et al. Squamous cell carcinoma of the seminal vesicle from zinner syndrome: a case report and review of literature. J Pathol Transl Med 2015;49:85-8.

124. Pavan N, Bucci S, Mazzon G, et al. It's not always varicocele: a strange case of Zinner syndrome. Can Urol Assoc J 2015;9:E535-8.

125. Juho YC, Wu ST, Tang SH, et al. An unexpected clinical feature of Zinner's syndrome - a case report. Urol Case Rep 2015;3:149-51.

126. García Asensio D, Fernández Martín M. Zinner syndrome diagnosed in a child. Radiologia 2016:58:73-4

127. Aghaways I, Ahmed SM. Endourologic intervention for management of infertility in a man with Zinner syndrome resulting in a natural pregnancy. J Endourol Case Rep 2016;2:71-3.

128. Hajji F, Hammoune N, Miloudi M, et al. Unusual variant of inverted Y ureteral duplication with an ipsilateral seminal vesicle cyst and renal dysgenesis. Ann R Coll Surg Engl 2017;99:e19-21.

129. Dogan F, Xhafa A, Bimbashi B. Excision of a giant seminal vesicle cyst associated with ipsilateral renal agenesis Zinner's Sendrom. J Endourol 2016;30:A417.

130. Shah S, Patel R, Sinha R, et al. Zinner syndrome: an unusual cause of bladder outflow obstruction. BJR Case Rep 2017;3:20160094

131.Bakloul F, Jakhlal N, Elghazoui A, et al. Seminal vesicle cyst: about a case. Pan Afr Med J 2016;25:68.

132.Gutierrez García MA, Estebanez Zarranz MJF, Crespo Crespo I, et al. Zinner syndrome, robotic management. European Urology Supplements 2016

133. Maré A, Liddell H, Chan HF. Ectopic ureteric insertion into a seminal vesicle cyst. A case report of recurrent UTI's and an unusual fistulous tract. BJU Int 2015;115:76.

134. Slaoui A, Regragui S, Lasri A, et al. Zinner's syndrome: report of two cases and review of the literature. Basic Clin Androl 2016;26:10

135. Canales-Casco N, Dominguez-Amillo A, Arrabal-Polo MA, et al. Hematospermia as a rare form of presentation of Zinner syndrome. Urology 2017;99:e15-6.

136. Prem G, Goh EH, Fam XI, et al. A rare presentation of urinary tract symptoms in a teenager: Zinner's syndrome. BJU Int 2017;120:33.

137. Chiapparrone G, Liguori G, Pavan N, et al. Fertility recovery after laparoscopic removal of hypertrophic seminal vesicle. J Urol 2017;197:e1060.

138. Cao JD, Zhu SL, Bai ZG, et al. Zinner syndrome: a case report and review of the literature. Zhonghua Nan Ke Xue 2017;23:452-4.

139. Ahmed A. Ipsilateral renal agenesis with megaureter, blind end proximal ureter and ureterocele in an adult. J Ayub Med Coll Abbottabad 2017;29:150-3.

140. Campora M, Olivero A, Toncini C, et al. Zinner syndrome: a diagnostic challenge. The aid of morphology, embryology, and immunohistochemistry. Urology 2017;108:e3-5.

141. Khanduri S, Katyal G, Sharma H, et al. Unique association of multiple seminal vesicle cysts with contralateral renal agenesis: a rare variant of Zinner syndrome. Cureus 2017;9:e1415.
a

142. Roth C, Götz G, Gräfe D, et al. Zinner syndrome: underestimated differential diagnosis in children with groin pain and retrovesical cyst. Pediatric Radiology 2018;48:S581-2.

143. Millman AL, Kroczak T, Ordon M. Images - Large symptomatic seminal vesicle cyst treated with robotic-assisted seminal vesiculectomy. Can Urol Assoc J 2019;13:E99-101.

44. Razdan S, Kryvenko ON, Razdan S. Robotic-assisted laparoscopic vesiculectomy in a patient with atypical Zinner syndrom presenting with large cyst involving bilateral seminal vesicles and vasa deferentia. Urol Case Rep 2018;18:79-81

145. Florim S, Oliveira V, Rocha D. Zinner syndrome presenting with intermittent scrotal pain in a young man. Radiol Case Rep 2018;13:1224-7.

146. Kord E, Zisman A, Darawsha AE, et al. Minimally invasive approach for treatment of seminal vesicle cyst associated with ipsilateral renal agenesis. Urol Int 2017;99:338-42.

147. Farooqui A, AlDhahir L, Mahfooz AB. Massive seminal vesicle cyst with ipsilateral renal agenesis - Zinner syndrome in a Saudi patient. Urol Ann 2018;10:333-5.

148. Brown M, Aiken W. Case report: Zinner's syndrome and a blind ending obstructed ureterocele: an unusual cause of lower urinary tract symptoms in a young man. BJU Int 2018,121:11-2.

149. El Mortaii H, Elatiqi K, El Hammaoui H, et al. Zinner's syndrome: a case report. Prog Urol 2018;28:464-5.

150. Briosa F, Valsassina R, Mira C, et al. Zinner and Mayer-Rokitansky-Küster-Hauser syndromes: when unilateral renal agenesis meets genital anomalies. BMJ Case Rep 2019;12:e229034.

151. Symeonidis EN, Gkekas C, Tsifountoudis I, et al. Incidental finding of Zinner syndrome in a Greek military recruit: case report of a rare clinical entity. Mil Med Res 2019;6:4.

52. Kori R, Bains L, Lal P, et al. Zinner syndrome mimicking bladder outlet obstruction managed with aspiration. Urol Ann 2019;11:449-52.

153.AlArifi M, Al-Gahwary M, Gomha M. The association of renal agenesis and ipsilateral seminal vesicle cyst: Zinner syndrome case report. Case Rep Urol 2019;2019:1242149.

154. Aslan S. A rare cause of chronic pelvic pain in young man: magnetic resonance imaging findings of Zinner's syndrome. Journal of Urological Surgery 2019;6:331-4.

155. Cito G, Sforza S, Gemma L, et al. Infertility case presentation in Zinner syndrome: can a long-lasting seminal tract obstruction cause secretory testicular injury? Andrologia 2019;51:e13436.

156. Bhukte S. Robot assisted laparoscopic excision of Seminal vesicle cyst: a rare entity (Zinner syndrome: Unilateral renal agenesis, ipsilateral seminal vesicle cyst and ejaculatory duct obstruction). BJU Int 2019;123:47-8.

157. Patil M, Shah R, Shah S, et al. Unusual variant of zinner syndrome presenting as cause of infertility in young male. Indian J Urol 2019;35:S31-2.

158.Sahare P, Shah S, Singh T, et al. A rare case of Zinners syndrome presenting as LUTS in young adult managed laparoscopicaly. Indian J Urol 2019;35:S31.

159. AlhajerI F, Salem S, Harraz A, et al. Recurrent epididymo-orchitis: uncommon presentation of zinner syndrome. J Endourol 2019;33:A370.

160. Corongiu E, Grande P, Olivieri V, et al. Minimally invasive management of a symptomatic case of Zinner's syndrome Laparoscopic seminal vesiculectomy and ipsilateral nephroureterectomy. Arch Ital Urol Androl 2019;91:58-9.

161. Chibelean BC, Tătaru OS, Borda A, et al. Zinner's syndrome - the value of clinical imaging and morphopathological findings for diagnosis. Journal of Interdisciplinary Medicine 2019;4:196-200.

162. Bryson CF, Delpe S, Tatzel S, et al. Robot-assisted excision of congenital mega-seminal vesicle associated with Zinner's syndrome. J Endourol Case Rep 2019;5:4-6.

163. Hergan B, Fellner FA, Akbari K. Incidental imaging findings suggesting Zinner syndrome in a young patient with pulmonary embolism: a case report. Radiol Case Rep 2020;15:437-41.

164. Yadav SP, Guriar K. Zinner syndrome: an unusual cause of bladder outflow obstruction. Indian J Urol 2020;36:S35.

165. Tan Z, Li B, Zhang L, et al. Classifying seminal vesicle cysts in the diagnosis and treatment of Zinner syndrome: a report of six cases and review of available literature. Andrologia 2020;52:e13397.

166. Jatal S. Say hi to zinner - Laparoscopic seminal vescial cyst excesion. Indian J Urol 2018;34:40. 